\title{
GEOGRAFÍA SOCIAL DEL TURISMO. UNA MIRADA CRÍTICA A LA PERCEPCIÓN DEL TURISMO Y A SU REPRESENTACIÓN ESPACIAL
}

\author{
Alfonso Fernández-Arroyo López-Manzanares*1 \\ Universidad de Castilla-La Mancha \\ https://orcid.org/0000-0001-8004-0878
}

\section{RESUMEN}

La Geografía Social del Turismo surge de una perspectiva sociológica en la aplicación del enfoque geográfico y aproximación al turismo. La novedad del término a nivel internacional revela el escaso recorrido de la crítica y la teoría social, así como de la irreflexión geográfica en este campo de estudios. El objeto de la investigación es un espacio social del turismo, representación espacial de un conocimiento-emancipación para proyectar un cambio social, una producción del espacio al margen de la racionalidad regulada por el mercado capitalista y su pedagogía neoliberal.

Palabras clave: Geografía Social del Turismo; espacio social del turismo; teoría social; producción del espacio; teoría de la regulación; representación espacial; plataforma científico-crítica.

\section{Social Geography of Tourism. A critical approach to perception of tourism and its spa- tial representation}

\section{ABSTRACT}

Social Geography of Tourism arises from a sociological perspective in the application of the geographical approach and his proximity to tourism. The originality of the term at the international level reveals the limited spread of criticism and social theory and, especially, geographical thoughtlessness in this field of studies. The object of this research is a social space of tourism, a spatial representation of a knowledge-emancipation to create a social

Fecha de aceptación. 4 de noviembre de 2019.

* Departamento de Geografía y Ordenación del Territorio. Universidad de Castilla-La Mancha. Avda. Camilo José Cela, s/n. 13071 CIUDAD REAL (España).E-mail: Alfonso.FArroyo@uclm.es

1 La realización de este trabajo de investigación se enmarca en el Plan Propio I+D+i de la Universidad de Castilla-La Mancha con la formalización de un contrato predoctoral cofinanciado por el Fondo Social Europeo [2015/4062]. 
change, a production of space outside the rationality regulated by the capitalist market and its neoliberalism pedagogy.

Keywords: Social Geography of Tourism; social space of tourism; social theory; space production; regulation theory; spatial representation; scientific-critical platform.

\section{INTRODUCCIÓN}

Una investigación puede tener varias aristas. En nuestro caso la línea está marcada por la intersección entre espacio y turismo, el primero objeto de la Geografía, el segundo de interés multidisciplinar, objeto de todos. La sociedad en su totalidad participa de este fenómeno voluntaria e involuntariamente, de forma activa o pasiva. Mientras el espacio unifica, uniformiza, nos sitúa a todos en un mismo plano - somos tiempo y espacio y no podemos prescindir de nuestra naturaleza-, el turismo reduce las relaciones sociales a un intercambio cultural mediado por la economía. Por ello, el turismo produce desequilibrios territoriales, distingue entre centros y periferia. También genera desigualdades sociales, clases sociales: distingue entre "mobile elites" y "vagabonds" como metafóricamente expresó el sociólogo y filósofo Zygmunt Bauman (1998: 87).

La dialéctica espacio-turismo vertebra el ensayo teórico que presentamos en un contexto o marco de trabajo abierto a la multidisciplinariedad, próximo a la Sociología, pero sin abandonar el lenguaje geográfico ni su objeto de estudio. Pues si bien aproximarse al turismo con enfoque geográfico requiere prescindir de teorías y conceptos preestablecidos, lo que no está determinado es la perspectiva que adoptaremos, coherente con nuestras creencias y convicciones. Al profundizar en la teoría social del espacio y de la regulación apreciamos un entorno científico-académico sumido en una "guerra cultural", la de dos formas irreconciliables de producir conocimiento.

En la dimensión de representaciones espaciales del turismo, aquella en la que nos situamos con la investigación, se puede diferenciar la influencia de corrientes y plataformas en constante evolución constituyendo la epistemología del campo de estudios del turismo. De este proceso surgen diferentes geografías del turismo: una Geografía Turística y una Geografía del Turismo con pretensión de ofrecer soluciones desde marcos pragmáticamente establecidos conforme el orden social vigente; así como una Geografía Social del Turismo cuya estructura aún por edificar se debe a un pensamiento crítico a la vez que utópico, aquel que profundiza en la raíz de la racionalidad del sistema social capitalista para ofrecer un estudio razonado de las posibles alternativas de fondo.

Autores con miradas diferenciadas coinciden en afirmar que el campo de estudios del turismo se encuentra en un importante momento de inflexión que abre una brecha para cuestionar tanto la férrea defensa del turismo como concepto aglutinador de actividades económicas, como los límites y limitaciones de los marcos convencionales de la Geografía de los que se nutre la representación de los espacios del turismo (Tribe, 2005: 5). Ante esta nueva tesitura, al geógrafo le quedan dos opciones: justificar el orden existente a través de la ocultación de conflictos perceptibles en la práctica espacial del turismo; 
o analizar la intencionalidad de ese encubrimiento y contemplar las posibilidades de un cambio social (Santos, 1990: 230).

Teniendo en cuenta tales apreciaciones, la investigación geográfica puede aportar al menos dos soluciones en lo que respecta al proyecto de reconstruir la práctica del turismo a través de su representación: la primera, revelar la inconsistencia de la visión neoclásica y funcionalista desde la que se define el espacio turístico como fragmentación necesaria para lograr la complementariedad competitiva entre lugares (Rosales, 2006: 132); y la segunda, la propuesta de una alternativa radicada en la reflexión profunda de la raíz del problema “que permita la búsqueda de lugares fuera de las rutas convencionales" (Pillet, 2012: 361).

\section{MARCO DE TRABAJO DE LA INVESTIGACIÓN}

Toda investigación está condicionada por los marcos de trabajo [frameworks] teóricos, conceptuales y analíticos - sobre los que se soporta la acción. Al proponer el turismo como objeto de estudio, abordado desde un enfoque geográfico, el marco teórico y conceptual se constituirá por la dualidad espacio-turismo (Coles et al., 2004, citado en Hall, 2009: 47). Las oscilaciones entre planteamientos neopositivistas y pospositivistas en un momento dominado por el eclecticismo obligan a no rechazar de forma global ninguna corriente geográfica en la investigación del turismo. Esto no evita que de forma generalizada el "compromiso social" se desplace del objeto central de la misma, dada la exigencia de resultados competitivos en un mercado académico que impide que "los jóvenes geógrafos, atraídos por la práctica, retomen nuevamente la teoría" (Pillet, 2008: 84).

Al respecto, el primer reto al que se enfrenta la investigación geográfica del turismo es el de superar los largos entrenamientos que implican aprender e interiorizar lo aprendido, comenzando por cuestionar el sentido de la investigación desde nuestras limitaciones, relacionadas con la forma en que percibimos el objeto de estudio y aplicamos el lenguaje geográfico en nuestras representaciones. Dicha barrera no se puede franquear sin pretender un recorrido reflexivo y crítico con la investigación, ya no hacia el cumplimiento de nuestros objetivos, sino hacia nosotros mismos, como investigadores. Tomar conciencia de esa dialéctica entre un afuera - lo investigado - y un adentro - el investigador - en el contexto de una Ciencia Social, como es la Geografía, y en el estudio de un fenómeno social, como es el turismo, es lo que nos aproxima a la Sociología.

Desde una perspectiva sociológica, más que social, se ha venido interpretando la tensión latente en la producción del conocimiento científico a través de dos ejes o fuerzas opuestas e interdependientes que se manifiestan en la investigación: una que emerge de la observación de los hechos, de una lectura crítica de las contradicciones latentes en la sociedad - pilar de la emancipación —; otra que se impone dogmáticamente al justificar el papel reaccionario de los poderes fácticos en la defensa del statu quo, eludiendo en todo caso la raíz de la contradicción — pilar de la regulación-(De Sousa, 1998: 87-88). Esta pugna entre emancipación y regulación fue conceptualizada por Habermas (1968, 1973: 32-33; citado en Santos, 2000: 246-247) al distinguir dos tendencias paralelas: "la racionalización por arriba y la racionalización por abajo". Desde miradas más recientes 
este conflicto se ha calificado "guerra cultural" [Kulturkampf], siendo posible "contra el saber, crear saberes y contra los saberes, contra-saberes” (De Sousa, 1993).

\subsection{Aproximación a la racionalidad social en la investigación geográfica del turismo}

Lo indicado hasta el momento nos remite a dos recorridos en lo relativo a la enseñanzaaprendizaje-investigación: uno que se vacía de humanismo y de crítica social al profundizar en un "conocimiento-regulación" coherente con los principios y valores históricamente legitimados; otro suscitado por la búsqueda de un "conocimiento-emancipación" que sirve al transitar desde el materialismo e idealismo hacia un estado de consciencia sobre la profundidad de los problemas ocasionados con la racionalidad enhebrada por la aguja del capitalismo (De Sousa, 2003: 260-261; 2006: 44; Sánchez Vázquez, 2006: 302). Una u otra forma de conocimiento revela creencias enfrentadas, condicionadas por aspectos "transteóricos" en cuanto que percibir y comunicar la realidad investigada sobrepasa los márgenes de lo epistemológico. Así, observamos que en los marcos convencionales en torno a los ejes conceptuales de la investigación - espacio y turismo - hay profundas limitaciones que coartan la producción de un conocimiento crítico al margen de la regulación.

Desgraciadamente, la Geografía hace tiempo que abandonó la reflexión profunda sobre su objeto de estudio en respuesta a la eficacia y competitividad que exige lo marcado por la agenda académica e institucional (Malpas, 2015: 205). El espacio, instrumentalizado y fuertemente influenciado por el "capitalismo cognitivo", con su pedagogía neoliberal, ha sido objeto de múltiples representaciones ahormadas a los intereses político-económicos de una élite social (Santos, 1990: 95; Benko, 2000: 6; Morales, 2007: 125), obteniendo como recompensa en lo relacionado con la representación de los espacios del turismo la inclusión de geógrafos en cuerpos administrativos o auxiliares de instituciones y empresas (Vera et al., 2011: 37-38). Por ello, el estudio del turismo en países fuertemente turistificados, como España, se ha visto extremadamente condicionado por "enfoques acríticos y legitimadores para con esta industria"(Blázquez y Cañada, 2011: 7), desplazando del debate público los deterioros sociales, ambientales y económicos por los que se hace evidente que "cualquier proyecto transformador debería incorporar la ruptura del modelo turístico-inmobiliario que ha marcado el devenir del capitalismo español desde la dictadura" (Murray, 2015: 397).

A partir de lo expresado, una mirada crítica al turismo con enfoque geográfico nos debería acercar a una Geografía Social del Turismo, a la representación del espacio turístico como un espacio social en oposición a la fría e inerte definición de "destino turístico" conforme a los principios sostenidos por el pilar de la regulación. En la representación de este espacio social del turismo "la pregunta esencial no es si existe o no un turismo alternativo, sino cómo se puede adoptar un enfoque alternativo al desarrollo del turismo en general" (Priestley, 1997: 264), cuestión urgente al considerar que esta práctica es "parte consustancial de las sociedades occidentales, de sus formas de vida, de su modo de entender el desarrollo"(Barrado y Ávila, 2010: 153). 


\subsection{Marco teórico-conceptual del espacio geográfico y social objeto de turistificación}

Cuando nos preguntamos por el objeto de la Geografía observamos que la racionalidad con la que se ha venido construyendo plantea dos extremos o patrones de representación: un "espacio" presa del positivismo lógico o neopositivismo, abstracción de la realidad por la que cómodamente se aplican principios y métodos cuantitativos; y un sistema de símbolos relacionados con la cultura y el relato estructuralista de la semántica del "lugar", de influencia fenomenológica, existencial e idealista (Casey, 1996: 33; Pillet, 2008: 64 y ss.). La enorme irreflexión y bajo nivel de teorización sobre el sentido dialéctico de los términos espacio y lugar conlleva un uso demasiado simple, muchas veces apropiados acríticamente para asimilar el uno al otro (Lindón y Hiernaux, 2006: 8; Malpas, 2015: 204). La evolución de tales conceptos en cada momento histórico está marcada por los sucesivos intentos de imponer un orden intelectual geográfico, político y social sobre la propia representación de los hechos (Smith, 1980: 59). El simple cuestionamiento de tales estructuras conceptuales resulta, por tanto, en sí mismo, un acto de subversión.

La escasa consolidación teórica al respecto - al no haberse producido una teoría unitaria a partir de las corrientes que configuraron la episteme geográfica del siglo $\mathrm{XX}-$, hace que en el actual contexto de eclecticismo y aparente moderación se imponga el pragmatismo a cambio de una clara actitud utilitarista por estar en los mercados. El carácter potencialmente transformador del lenguaje geográfico queda reducido así al discurso liberal que no concibe que haya espacio al margen de la lógica del beneficio, lo que ha venido a imponer en todos los lugares una única racionalidad (Pillet, 2008: 84 y 90; López, 2018: 157). Al hablar de lugar se desvela la "funcionalización del mundo" a través de los procesos relacionales de dependencia y dominio-control-dominación de unos lugares sobre otros (Santos, 1990: 137; 1996: 144; Ortega Valcárcel, 2000: 339).

En cuanto a la idea de espacio geográfico, el problema cognitivo proviene de la "desocialización" a la que se ha sometido, transformado en un espacio de apariencias cuya representación escinde su ineludible inter-composición triádica: "sociality", "spaciality" and "historically" (Soja; 1997: 72; Pillet, 2008: 75). Siempre en alusión a esa múltiple dimensionalidad de un "espacio-tiempo social" en el que la sociedad actúa como el elemento motriz de su producción (Lefebvre, 2013: 74). Conforme a esta idea, "lo espacial" no solo se concibe como resultado sino como parte de la explicación, percibiendo el espacio como producto de la práctica o prácticas determinadas por el valor social de los hechos representados. Por ello, la construcción del lenguaje geográfico no se debería formular en base a la dialéctica espacio-lugar, sino a la dialéctica espacio-sociedad (Massey, 1984: 101; 1991: 25-26; Santos, 2000: 66).

Una u otra forma de representar el objeto geográfico repercutirá en las conductas sociales supeditadas a la lógica del capital, especialmente a través de sus prácticas de consumo, cotidianas y excepcionales, desde la cesta de la compra al turismo. Considerar esta forma de descifrar el espacio social en lo relacionado con el turismo supone profundizar en la raíz del sentido de acciones no conscientes o espontáneas más bien que inconscientes, así como en la regulación de los marcos herméticos y disciplinares que suprimen formas de investigación declarándolas imposibles o impropias (Albet, 1988: 11; De Sousa, 1998: 252-253). En todo caso, aproximarnos a la teoría social de la regulación y de la produc- 
ción del espacio para promover la idea de un "conocimiento-emancipación" con enfoque geográfico "supone invertir la formulación epistemológica dominante durante decenios" (Ortega Valcárcel, 2004: 27 y 33).

A esta integración entre enfoque geográfico y sociológico, Steinmetz (1923: 217 y 223; citado en Luis Gómez, 1983) lo denominó "Sociografía", siendo posible acuñar un nuevo término: una Sociografía del Turismo o Geografía Social del Turismo como forma de superar las limitaciones de la "racionalidad espacial o razón cartográfica" cuyo problema es más ontológico que epistemológico, dada su dificultad para incorporar lo social al esquema teórico del espacio (Bailey, 2014: 92-93). Por tales cuestiones es prioritaria la toma de conciencia del geógrafo en cuanto al poder latente de sus representaciones, sabiendo que la funcionalización del lugar promovida con la producción del espacio objeto del ocio y el turismo no solo seguirán al discurso de la sociedad dominante, sino que crearán una cosmovisión - gaze-(Korstanje, 2013: 15).

\subsection{Marco integrador y contexto de los estudios contemporáneos del turismo}

Al trasladar la dialéctica regulación-emancipación a la forma en que se ha percibido y concebido la práctica del turismo ponemos de relevancia el fuerte sesgo descriptivo y empírico que ha determinado su "indisciplina" como campo de estudios heterogéneo: dada la contracción teórica por la asunción de una fuerte crisis de reflexión se asume con unanimidad la falta de un marco unificador que permita su autonomía como disciplina (Almirón, 2004: 168; Tribe, 2004: 49; Vera et al., 2011: 68; Pearce, 2012: 7). Si bien es cierto que el "fenómeno" turístico - como se dio en llamar desde un principio- pudiera tener un recorrido mayor de lo que se piensa, solo a partir de la década de 1980 empezó a adquirir interés la conceptualización de su espacio geográfico en España (Valenzuela, 1986: 47; Muñoz, 1992: 15; Hall, 2009: 35 y 51).

Esta entre otras cuestiones ha propiciado que no haya sido posible consensuar una explicación razonable de la naturaleza del espacio turístico y de su construcción, menos aún desde una perspectiva social (Vera et al., 1997: 7; Hiernaux, 2006: 423; Anton y González, 2008). La teoría en el conjunto de la investigación del turismo se plantea como un adorno, una cuestión de obligado cumplimiento en la introducción de investigaciones con un marcado carácter aplicado, con la finalidad de aparentar "credibilidad" sin tener la necesidad de avanzar en cuestiones teóricas dado el reconocimiento general de este tipo de estudios (Cooper et al., 2007: 50; Castillo y Panosso, 2011: 386). Solo "hay que demostrar que se conoce", se suele decir. Tal y como irónicamente se ha expresado: "al fin y al cabo, no saber bien qué es el turismo, no es tan grave" (Muñoz, 1992: 7).

En el marco de estudios geográficos esa falta de reflexión se ha intentado excusar al señalar que a pesar de su juventud relativa "la consolidación y madurez alcanzadas por la Geografía del Turismo, Ocio y Recreación han comportado implícitamente su conformación teórico-conceptual y metodológica" (Cooper et al., 2007: 43; Vera et al., 2011: 53; Pearce, 2013: 918). Esta forma de concebir la práctica del turismo como hiperreal, es decir, con capacidad para teorizarse a sí misma, es lo que ha propiciado que muchos de los especialistas que se aproximan a este campo de estudio, entre ellos el creciente ejército de "turismólogos" y expertos incorporados a las filas del ámbito administrativo y de los 
negocios, conciban el turismo como algo ajeno a la sociedad, así como en particular a los problemas ocasionados de su percepción eminentemente economicista.

Todo ello ha determinado que el campo de estudios geográficos del turismo se limite básicamente a dos formas de abordar el fenómeno: una "Geografía Turística", producto del conocimiento generado con la descripción de los principales atractivos y zonas turísticas de un país o región, interesada por lo general en la definición de los diferentes usos y modalidades turísticas asociadas a la idea de destino; y una "Geografía del Turismo", gran triunfadora en el contexto de especulación del suelo y del territorio o "patrimonio territorial", dedicada a analizar flujos y patrones de distribución adoptando modelos funcionales en su finalidad planificadora (Calabuig y Ministral, 1999: 18; Pillet, 2016; Troitiño y Troitiño, 2018: 221). Los resultados de este tipo de estudios vienen validados política y económicamente por el interés "descriptor y localizador de los atractivos y recursos turísticos" (Vera et al., 1997: 44).

Miembros de la comunidad científica con autoridad en este campo no dudan en señalar la problemática de este tipo de estudios bajo demanda, pues corrobora que la realidad, por injusta que parezca, se impone a la reflexión teórica. Y es que la teorización sobre la naturaleza social del turismo se ha calificado de polémica, minada de escollos, abocando al desistimiento por ser ignorada o atacada desde las epistemologías del Norte: cualquier propuesta contraria a la tendencia general es calificada de "imposible" o "ridícula", mientras lo que se está produciendo es un conocimiento al margen de la compleja realidad del fenómeno (Tribe, 2004: 57; 2005: 5). Por tales motivos queda aún pendiente el desarrollo de una Geografía Social del Turismo en cuyo marco integrador se soporte la representación de un tercer espacio, un espacio para la esperanza o espacio social del turismo que revele y ponga en crisis la racionalidad turística occidental.

\section{OBJETIVO, METODOLOGÍA Y ESTRUCTURA DE LA INVESTIGACIÓN}

¿A qué propósito responde, pues, una aproximación geográfica al espacio social del turismo? En primer lugar, a generar la consciencia necesaria para recobrar la unidad de los elementos disociados por una racionalidad y conocimiento fragmentados, identificando problemas y contradicciones a veces ocultas e indiscernibles. De buscar la procedencia intelectual de este "conocimiento-emancipación" debemos remitirnos a La production de l'espace proclamada en los años setenta por Henri Lefebvre, la obra que más vigorosamente y con éxito ha accionado la teoría social del espacio. Este texto traducido al español en 2013 tiene como base "transteórica" el cuestionamiento del modelo social capitalista, aportando un marco analítico útil para entender cómo los procesos de socialización en espacios determinados generan grupos sociales, y cómo éstos transforman los lugares y se transforman a sí mismos a través de sus prácticas y representaciones (Ortega Valcárcel, 2004: 27-28; Benach y Albet, 2010: 204 y ss.).

La interpretación que hace Soja (2003: 1-2) sobre esta teoría le llevó igualmente a considerar que adscribirse a este proyecto supone la voluntad de generar nuevas conciencias acerca de que: "we are, and always have been, intrinsicall y spatial beings, active participants in the social construction of our embracing spatialities". Se hace evidente, por tanto, que esta teoría haya sido mejor acogida en la periferia: el objetivo no es, ni 
más ni menos, que impulsar cambios en y desde los centros de conocimiento donde el espacio social debería ser, por prudencia y por responsabilidad, una de las aspiraciones básicas del geógrafo (Massey, 2004: 80; Lindón y Hiernaux, 2006: 9). Tales cuestiones invitan a preguntarse por la utilidad social que adquiere el geógrafo dada su capacidad para ofrecer lecturas alternativas a las representaciones espaciales fruto de las teorías llamadas "burguesas", de corte liberal, como base para movilizar las diferencias y el derecho a la diferencia de "la periferia explotada" (Lacoste, 1978: 30; De Sousa, 2006: 53; Lefebvre, 2013: 120 y ss.).

Para ello establecemos como punto de partida la revisión de la literatura especializada, de la que extraemos la perspectiva que alimenta nuestro marco teórico sobre la dualidad conceptual espacio-turismo y de la que señalamos la falta de un término conciso para referirse a una mirada crítica del turismo, sustentada en la integración del enfoque geográfico y social. Por otro lado, el objetivo planteado con la investigación nos hace pensar en una "praxis" a partir de la cual establecer las fases de la investigación para una posterior estructuración de lo que denominaremos Geografía Social del Turismo.

En primer lugar, la lectura crítica de textos según el método de investigación hermenéutica nos lleva a cuestionar la racionalidad implícita en la investigación geográfica del turismo haciendo explícitas ideologías, tensiones y legitimaciones que rigen y orientan los modelos de representación convencional, así como la obtención de resultados que limitan las aspiraciones regenerativas del pensamiento sin las que cualquier conocimiento profundizará en su propia degeneración hasta colapsar.

En segundo lugar, la exposición del debate como marco integrador de la teoría social del espacio y del conocimiento generado en el campo de estudios del turismo nos lleva a plantear la idea de un proyecto alternativo. Se trata de contrastar el sentido de la representación del turismo para exponer una "idea o utopía de emancipación social, humana, o de una nueva sociedad como alternativa social en la que desaparezcan los males sociales criticados" (Sánchez Vázquez, 2006: 302). No es solo una voluntad creativa, sino "la proposición de un espacio alternativo, contra-planes y contra-proyectos que frustren las estrategias, los planes y los programas impuestos desde arriba" (Lefebvre, 2013: 413-414).

La estructura seguida en este ensayo plantea un análisis de la evolución epistemológica del campo de estudios del turismo, pues una vez ganemos claridad de ideas en cuanto a las corrientes de pensamiento que han condicionado nuestra percepción podremos reformular la forma de concebir el turismo y su espacialidad. Para ello, incidimos en una idea: el espacio social del turismo objeto de una Geografía Social del Turismo. En el fondo subyace la idea de que si somos capaces de cambiar tan solo una de las dimensiones constitutivas de la racionalidad del espacio - percibido, concebido y vivido- , fundamentalmente la forma de concebirlo y representarlo, estaremos impulsando cambios en la práctica social del turismo transformando, por tanto, el sentido de su producción espacial.

Finalmente, a partir de la lógica discursiva y propósito manifestado, reflexionamos sobre la doble racionalidad subyacente en la representación del turismo actual, profundizando en el sentido de la investigación para remitirnos a dos formas confrontadas de percibir la práctica social y espacial del turismo con efecto en su representación: como espacio economía-mundo del turismo y como espacio social del turismo, para terminar con las conclusiones obtenidas del ensayo. Lo expuesto aquí se recoge de manera más extensa 
en el trabajo de investigación que adquirió forma de tesis doctoral bajo la dirección del catedrático D. Félix Pillet Capdepón al aplicar el marco teórico y conceptual desglosado a un territorio concreto, obteniendo un resultado satisfactorio (Fernández-Arroyo, 2019).

\section{MOMENTOS, ETAPAS Y PLATAFORMAS DE LA EPISTEMOLOGÍA DEL TURISMO}

En pocas ocasiones se ha dedicado tiempo al estudio de la evolución epistemológica del turismo, limitado, por lo general, a un análisis descriptivo del fenómeno como actividad económica sin reparar en porqué lo percibimos así, supeditado a la idea de industria cultural y de servicios. De comprender la construcción del pensamiento turístico como un proceso sin rupturas, una "continua revolución", debemos plantear que las diferentes corrientes y tendencias en la investigación se han ido solapando e interpelándose unas a otras hasta alcanzar cierto nivel de maduración (Hall y Page, 2006: 16). En nuestro caso, describimos un proceso evolutivo por el que se distinguen "plataformas" constituidas por el carácter dominante de la investigación en cada una de las "etapas" delimitadas por procesos de ruptura calificados "momentos" (figura 1).

Jafar Jafari (2005: 50) nos propone la idea de "plataforma" como soporte conceptual del sentido o valoración social de una u otra forma de percibir y concebir el turismo y su espacialidad - "plataforma apologética", "plataforma precautoria", "plataforma adaptativa", "plataforma científico-céntrica" y "plataforma de interés público"-, para en la actualidad celebrar junto con la opinión pública que el turismo se haya convertido en "una decisiva fuerza económica global y una gigantesca industria mundial". Por otro lado, la caracterización de este proceso por "etapas" a cargo de Denzin y Lincoln (1998), actualizada por Jenny Phillimore y Lisa Goodson (2004), advierte ciertos periodos de continuidad y ruptura analizados desde una perspectiva con carácter cualitativo - "traditional period", "modernist period", "blurred generes" y "crisis in representation"-.

Resultado de esta asociación de "plataformas" y "etapas" podemos distinguir aspectos comunes e interpretaciones divergentes en la evolución del pensamiento científico-académico del turismo, accediendo a visiones diferenciadas según las dos grandes corrientes que se intentaron unificar por medio de la Doctrina General del Turismo (DGT): la económico-empresarial y administrativa del turismo con la perspectiva sociológica (Castillo, 2011: 517-518). En el fondo buscamos la comprensión sistematizada de la relación entre racionalidad y representación del turismo, pues esta constituye la base ontológica y epistemológica desde la que justificar el surgimiento de un momento de cambio del cual nos sentimos partícipes, una etapa de eclecticismo en la que se reconocen tensiones entre la producción de un "conocimiento-regulación" y un "conocimiento-emancipación" que asociamos a la idea de plataforma científico-crítica.

A su vez, hacemos notar puntos de ruptura entre "plataformas" y "etapas" según un proceso de revolución social y del pensamiento cuya sucesión se marca por "momentos" concretos, esta vez caracterizados por Alicia Lindón (2004) al señalar cambios de tendencia en la historia reciente (1946, 1961-1967 y 1981). De las tensiones cotidianas se derivan momentos históricos en los que la "riqueza social" o capacidad para favorecer el progreso social se sobrepone a la saturación existencial provocada por la tendencia repetitiva $-\sin$ 
utopía - de condiciones de "miseria" o represión de posibles tentativas a favorecer una verdadera transformación (Lefebvre, 1961: 348-351; citado en Lindón, 2004: 46-47).

Con el objetivo de reflexionar acerca de la difícil conformación de un "conocimientoemancipación" negado por otro, objeto de regulación, procedemos con la confrontación de visiones diferentes en cuanto a la evolución referida. Esto debería ayudar a entender la sucesión de miradas al turismo en concordancia con un trasfondo o racionalidad condicionada por la percepción, concepción y experiencia cambiante de la vida social. El marco temporal de este proceso abarca desde la segunda mitad del siglo XX hasta la actualidad, tomando 1946 como momento inicial en la conformación epistemológica del actual cuerpo de estudios del turismo, "pues como defiende Francesch (2004) o indica Prats (1997: 40), no puede hablarse de turismo tal y como lo entendemos hoy más allá de la Segunda Guerra Mundial" (Arnadis, 2017: 2).

\section{Figura 1}

\section{ETAPAS Y PLATAFORMAS DEL PENSAMIENTO TURÍSTICO}

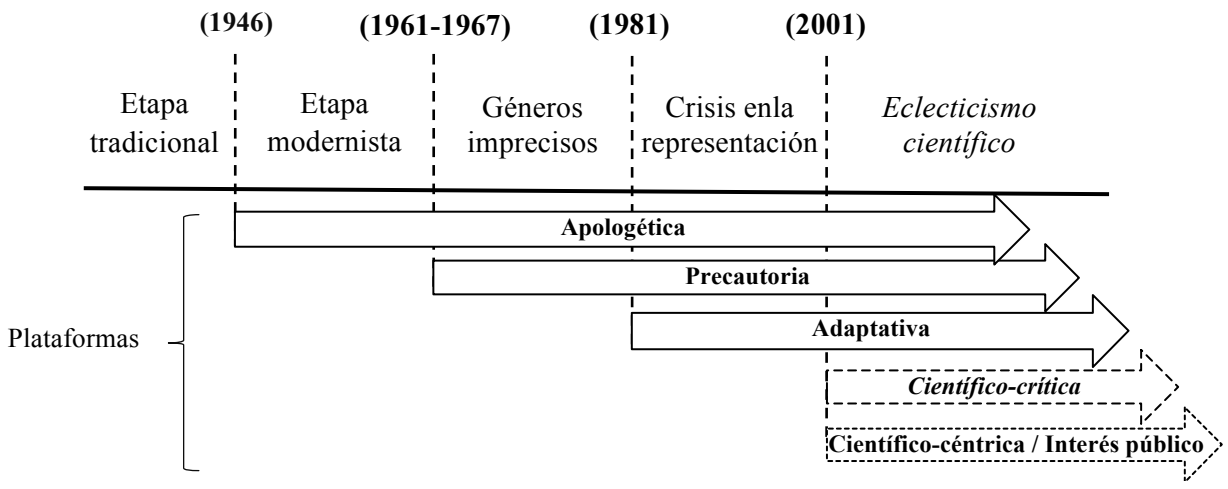

Fuente: Elaboración propia a partir de Lindón (2004), Phillimore y Goodson (2004) y Jafari (2005).

\subsection{De la etapa tradicional a la modernista: el surgimiento de la plataforma apolo- gética}

Finalizada la Segunda Guerra Mundial (1939-1945) se abrió un momento de ruptura con la etapa "tradicional" de la que se ha destacado el enfoque cualitativo de los estudios turísticos, generalmente ocupados en el proceso colonialista y con el objetivo de incidir en la pobreza y en la cultura del "otro" (Phillimore y Goodson, 2004: 9 y 12). En 1946, la esperanza en un poder imaginativo hacía prever la posibilidad de un cambio social. La "riqueza de lo cotidiano" favorecía la coexistencia de opuestos y la capacidad de concebir lo nuevo estaba en el aire, se representaba en multitud de círculos. Aunque se sospecha que la esencia de ese imaginario no era tan creativa, sino que estaba en la evocación, en la resurrección del pasado, es decir, en la repetición de una memoria manipulable (Lindón, 2004: 49). 
Comenzó la "etapa modernista" (1947-1960) en el campo de estudios del turismo y se impuso una corriente de cariz apologético encabezada por "grupos de interés" que promovían la idea del turismo como industria beneficiosa para la generación de empleo, divisas y alternativas en países en desarrollo; actividad económica multiplicadora sin perjuicio del medio natural y humano, revitalizadora de tradiciones culturales y folclóricas e, incluso, facilitadora de la paz mundial (Jafari, 2005: 41; Cooper et al., 2007: 41). Las escuelas norteamericanas de hostelería y turismo ejercieron una notable influencia en el surgimiento de la plataforma cuyos miembros compartían la preferencia por el carácter cuantitativo de la corriente positivista en la investigación (Hall y Page, 2006: 11).

El espacio geográfico objeto de representación de la "plataforma apologética" se amoldaba a las preferencias gubernamentales. En el caso británico, los ejemplos de este interés por impulsar las cifras del turismo en los destinos vacacionales costeros se encuentran en la investigación de autores como: Gilbert, 1939, 1949, 1954; Spencer y Thomas, 1948; Withington, 1961; o Sopher, 1968 (Hall y Page, 2006: 12). En el caso español, esta intencionalidad "transturística" es aún más evidente, promovida por el interés político de abandonar un modelo turístico agotado, marcado por la autarquía del régimen, con el propósito de propiciar "el acercamiento entre la España franquista y las instituciones internacionales - de los países del capitalismo avanzado - que supuestamente debían velar por ciertos valores como los de la democracia y la libertad" (Murray, 2015: 24).

\subsection{Una etapa de géneros imprecisos marcada por la precautoria en la investigación}

La declaración del Año Internacional del Turismo (1967) por parte de la Organización de las Naciones Unidas (ONU) dio paso a una nueva etapa calificada de "géneros imprecisos" (1968-1980). El auge de la visión crítica sobre el turismo en aquel momento hace que se haya caracterizado el surgimiento de una plataforma "precautoria", "premonitoria" o "socioantropológica" (Jafari, 2005: 4; Castillo, 2011: 518). Contraria al discurso apologético del turismo, la corriente generada por esta plataforma estuvo marcada por la incertidumbre, liberando fuertes tensiones en clave turística e impulsando el radicalismo atemperado de autores como Chadefaud, así como el rechazo a la neutralidad generalizada en las Ciencias Sociales y a la rigidez de los límites disciplinares (Luis Gómez, 1987: 23 y ss.; Callizo, 1991: 183).

$\mathrm{Su}$ impulso se debe a un momento en el que la complejidad o "riqueza social" se retrotrajo ante la expansión de la "miseria" (1961-1967). Se impuso la regulación, antes aparente, ahora con una fáctica expresión. La crítica a lo cotidiano se marcó la tarea de desenmascarar los nombres otorgados para dar normalidad a las contradicciones de la época. Este tipo de investigación encontró fuertes impedimentos, limitando la posibilidad de desvelar los rasgos centrales de una sociedad constituida como un nuevo reino controlado. El propio Henri Lefebvre (2013: 360) empleó el término "sociedad burocrática de consumo dirigido" para expresar la regulación de prácticas y relaciones socioespaciales conforme al principio de mercado, aplacando en todo caso el deseo de ruptura con lo cotidiano mediante supuestas necesidades programadas - "sociedad del ocio"- .

Algunos investigadores relacionados con la "plataforma precautoria", en auge durante la etapa "géneros imprecisos" (1968-1980), comenzaron a combinar teorías tradicionales con 
modelos y enfoques desarrollados en la etapa anterior (1947-1960). Se recuperó la preocupación por la relación turismo-colonización y se resignificó el concepto "periferia", hasta el momento utilizado en términos de "periferialidad" para distinguir entre viajes de placer hacia zonas periféricas y viajes de negocios o educativos hacia zonas urbanas. La obra de L. Turner y J. Ash (1975) - The golden ordes: International tourism and the pleasure periphery - es sin duda la más representativa al "identificar las razones por las que este tipo de organización estaba basada en la distribución desigual del poder en el seno de una economía y de una sociedad donde el núcleo domina y la periferia es dependiente" (Hall, 2009: 293).

La nueva generación de investigadores preocupados por los patrones del turismo en oposición al proyecto positivista llevó a explorar nuevas posibilidades: recursos fotográficos y publicitarios, experiencias personales, entrevistas en profundidad (Phillimore y Goodson, 2004: 14). La preocupación por las características del empleo generado, por los impactos ecológicos y culturales, así como por los desequilibrios estructurales fue la constante, adoptando la idea de "capacidad de carga" en alusión al manejo de recursos y propiedades (Jafari, 2005: 42). En el caso anglosajón aumentó la preocupación por el contexto geográfico del sur asiático poscolonial y el encubrimiento de un proyecto de transiciones imprecisas al negar que las nuevas zonas de destino albergaban en su interior el potencial de su propia destrucción, pues con su comercialización en términos de mercado solo quedaba agotar las cualidades que originalmente atraen a los turistas hacia la periferia (Hall y Page, 2006: 12). En España, por el contrario, los franquistas anularon la creatividad acallando la crítica a la estrategia propagandística del régimen en el extranjero (Correyero, 2003)².

\subsection{La etapa de crisis en la representación y el dominio de la plataforma adaptativa}

La simbólica ruptura del orden social vigente con la caída del Muro de Berlín (1989) ha permitido que autores de contrastada cosmovisión coincidan en señalar el solapamiento de dos perspectivas opuestas en la "etapa de crisis en la representación" (1982-2000) (Phillimore y Goodson, 2004: 16; Jafari, 2005: 42). El momento previo (1981) revelaría que en el ámbito del conocimiento científico-académico y social la crítica fracasó: "de la hipercrítica y la revalorización de lo vivido como conceptos se pasó a la dominación de lo vivido soslayando lo concebido" (Lindón, 2004: 57). Se puede hablar de un creciente interés por la simple anatomía superficial de las estructuras y del lenguaje, del abandono controlado de la alienación como concepto y del humanismo como proyecto de la sociedad que se había ido moldeando en la etapa anterior ${ }^{3}$.

Tres décadas más tarde la afirmación de lo ocurrido se ha expresado con la popular noción de posverdad: la verdad representada adquiere mayor significado que la experien-

2 Son evidentes los motivos por los que en España todavía existe resistencia al desarrollo de esta corriente. Cómo contradecir "el «milagro español»", a pesar de que "se sustentaba en unos elevados costes sociales —emigración, explotación de la clase trabajadora, infraviviendas en las grandes ciudades, represión política, etc. - , que no se expresaban en las cuentas de resultados microeconómicos ni macroeconómicos. Unos costes sociales que también incorporarían unos crecientes impactos ecológicos" (Murray, 2015: 26).

3 Guy Debord, en su libro "La Sociedad del espectáculo" (1967), caracterizó el capitalismo avanzado como un conversor permanente de todo lo real en una proliferación de imágenes, en un gran espectáculo, llegando a decir que: "en la sociedad del espectáculo la mentira es un momento más de la verdad, y la verdad un momento de la mentira” (Ibañez, 2017: 21). 
cia; la realidad aparente cobra más validez y reconocimiento que la propia realidad ${ }^{4}$. Así, en el contexto de posmodernidad, las corrientes apologética y precautoria del turismo fueron fagocitadas por la "plataforma adaptativa", de apariencia neutral. La corriente impulsada en esta etapa aglutinó la defensa de un cambio de prioridades asumiendo cómodamente esquemas, teorías y metodologías preelaboradas, inhibidoras de la capacidad crítica en la investigación. Esto dirimió la resistencia a la socialización del descenso en las tasas de beneficios empresariales e impulsó el enfoque mercadológico de influencia norteamericana, aumentando la profesionalización de los agentes relacionados con el turismo en los perfiles del marketing, la comercialización y la gestión de los negocios turísticos (Williams, 1994: 42; Castillo, 2007: 83-84; 2011: 518).

Concretamente, desde los centros de poder geográfico y del conocimiento, estatales y regionales, se generalizó la representación de prácticas alternativas basadas en experiencias gratificantes para el turista, sin olvidar la intención de incentivar el desarrollo de nuevos nichos de mercado en la periferia. El uso de apelativos tales como cultural o sostenible justificó prácticas en apariencia respetuosas y diferenciadas de un turismo de masas. Si bien debemos reconocer que algunas prácticas de turismo "sostenible" o "responsable" se encuentran más cercanas a alcanzar unos parámetros e indicadores óptimos (Priestley, 1997: 267-268; Cañizares, 2013: 88), “el verdadero impacto sociocultural del turismo va mucho más allá y engloba efectos directos e indirectos” (Cooper et al., 2007: 282).

Con este tipo de representación generalizada, tanto en España como internacionalmente, se ha obtenido el beneplácito de la opinión pública al incentivo estatal de proyectos difícilmente ejecutables según el criterio de competitividad necesario para mantenerse en los mercados (Muñoz, 1992: 311; Shaw y Williams, 1998: 157). Por ejemplo, al hablar de ecoturismo desde diferentes ámbitos se ha pretendido llamar "la atención de empresarios y gobiernos, así como de investigadores y académicos, a menudo como coartada para mejorar beneficios entre los primeros" (Jafari, 2005: 42-43), sabiendo que "cualquier negocio puede autodenominarse «empresa de ecoturismo» [y que] muchos turoperadores tienen una extraña idea de lo que significa ser «verde»" (Cooper et al., 2007: 270).

\subsection{Etapa actual: eclecticismo científico en el campo de estudios del turismo}

Con el cambio de siglo se hizo visible el elevado nivel de escepticismo y eclecticismo conceptual unido al pragmatismo defendido por el posmodernismo (Pillet, 2008: 84 y ss.). En el campo de estudios del turismo esto ha supuesto "la ruptura de las grandes narraciones dominantes" (Cohen, 2005: 14). Como tantos otros teóricos de la globalización y de la posmodernidad próximos a este campo de estudios, John Urry (2011: 18 y ss.) planteó que las consecutivas crisis sociales, económicas y ambientales evidencian un "cambio de ciclo" impulsado por la percepción del "incremento masivo de la miseria". La idea de transición marcada por una creciente sensación de control y seguridad cobró fuerza a partir de los hechos rememorados en la "Zona Cero", siendo complejo caracterizar el cambio de tendencia como demuestra la divergencia de las conclusiones a las que llegan los autores considerados.

4 Arias, M.: Genealogía de la posverdad, en prensa el 30 de marzo de 2017. EL PAÍS. Disponible en http:// elpais.com/elpais/2017/03/15/opinion/1489602203_923922.html 
Mientras Jafari (2005: 43) planteó que a partir de las plataformas consideradas hasta el momento - "apologética", "precautoria" y "adaptativa" - se impuso un nuevo cuerpo multidisciplinar de especialistas ocupados en el análisis sistémico del turismo para ofrecer representaciones mucho más científicas, Phillimore y Goodson (2004: 17) señalaron el incipiente recorrido de una etapa que supondría un posible cambio: "in order to move to wards more interpretive, qualitative tourism research, it is necessary to depart from more static, quantitative and positivist knowledge bases to more dynamic, experiential and reflexive approaches".

Así, frente al surgimiento de la "plataforma científico-céntrica" de raíz apologética caracterizada por el profesor de Turismo de la Universidad de Wisconsin-Stout (Estados Unidos), lo que describen las investigadoras de la Universidad de Birmingham (Reino Unido) es una nueva generación de autores cuya percepción y concepción del turismo, tras "una década de cambios", emerge en ciertos ámbitos de investigación desmarcados de la influencia de las escuelas de negocios anglosajonas en forma de un inesperado "giro cultural" (Hiernaux, 2008a; 2008b). El neozelandés Douglas Pearce (2012: 173) señaló el auge de focos emergentes y periféricos que se podrían enmarcar dentro de la noción plataforma científico-crítica, destacando la importancia de sus hallazgos para el enriquecimiento del campo de estudios turísticos por lo diverso de sus aportaciones.

En paralelo al desarrollo de dos corrientes opuestas, soportadas en sus respectivas plataformas - "científico-céntrica" y científico-crítica-, en la etapa de eclecticismo actual emerge una fuerza con voluntad homogeneizadora que Jafari (2005: 44 y ss.) ha denominado "plataforma de interés público". Su meta es "apropiarse del turismo" en su más amplio sentido. A través de la difusión de imágenes estereotipadas de la realidad objeto de regulación se reafirma su condición de actividad económica como concepto, para situarla en su "legítimo" lugar junto al resto de industrias y disciplinas. En este caso, la idea de plataforma no obedece a ninguna corriente científica, sino a un trasfondo ideológico cuya razón se ha institucionalizado por la presión de organismos intergubernamentales: United Nations Educational, Scientific and Cultural Organization (UNESCO); United Nations Development Programme (UNDP); United Nations World Tourism Organization (UNWTO); etc.

Ahora, cada vez más, la lógica neoliberal trasladada con la funcionalización turística del lugar actúa como un "factor de transformación y un componente estructural de nuestra sociedad" (Vera et al., 1997: 21). De ahí que el reconocimiento de la "plataforma científico-céntrica" avalada por la "plataforma de interés público" favorezca la creencia de lo deseable e inevitable que resulta la turistificación de toda localización en base a unos intereses globalizados (Hiernaux, 2014: 143). Tales valoraciones aparentemente fundamentadas en términos científicos incentivan la férrea defensa del turismo por organizaciones gubernamentales, intersectoriales y laborales que vienen a avalar la orientación de todo tipo de recursos, públicos y privados, para garantizar el buen funcionamiento del sistema capitalista y de las estructuras sociales que lo sustentan (Shaw y Williams, 1998: 61)5. Sobre esta distopía se construye la mayor parte de la investigación

$5 \quad$ El World Travel and Tourism Council (WTTC) entre otras organizaciones internacionales compuestas por ejecutivos de compañías privadas de aviación, transportes, hoteles y agencias de viaje tienen como finalidad ejercer presión sobre el sector público en "la mejora del reconocimiento de la importancia del turismo y la eliminación de barreras que restringen el crecimiento del turismo" (Sancho, 1998: 209). 
geográfica del turismo en la actualidad, dejando poco margen a percepciones alternativas y posibilitadoras de otra representación espacial del turismo.

\section{PERCEPCIÓN Y CONCEPCIÓN DEL TURISMO EN LA ETAPA ACTUAL}

La etapa actual o de eclecticismo científico resulta de la creciente contradicción entre lo representado y la representación, situación heredada de la etapa anterior e impulsada por la agenda política calificada de "interés público", ya que no está ni se espera la crítica al modelo capitalista de crecimiento turístico promovido con la lógica del pensamiento neoliberal ${ }^{6}$. En notable sintonía, los estudios posmodernos sobre turismo han resultado no ser tan reaccionarios ni rupturistas como se esperaba. Definitivamente, la investigación actual se viene sustentando en el triunfo de un "posmodernismo reconfortante o de celebración", contrario al previsto "posmodernismo inquietante o de oposición"(De Sousa, 1998: 37 y 374).

A fin de cuentas, la lectura acrítica de los cambios y conquistas del turista posmoderno no ha dejado de ser una paradoja de los últimos tiempos al no cuestionarse la racionalidad matricial que justifica nuevas formas de violencia colonial y de clase social auspiciadas por el lenguaje geográfico. Concretamente, aquel que intencionada o involuntariamente ha avalado el desarrollo de la industria del turismo transformando todo territorio rentable en "recurso económico" con valor de cambio. De ahí que se deban señalar contradicciones poco novedosas y sí persistentes en los estudios posmodernos, en ocasiones autodenominados así para distanciarse de los problemas de base que atañen al turismo y a la forma en que se ha representado (Hiernaux, 2006: 417 y ss.; Castillo, 2011: 524 y 528).

Por ello, en la etapa actual se llega a defender la incapacidad de integrar en un único "Campo de Estudios del Turismo" (CET) las disciplinas que se ocupan del marketing, de la estrategia o de la gestión con aquellas preocupadas por otros aspectos al margen de la mercadología del turismo. Según John Tribe (2004: 50-51), una "hibridación" de marcos - conceptos, ideas, enfoques, métodos, etc.- hubiera permitido generar un conocimiento verdaderamente "interdisciplinar" de aislar la noción de turismo de toda ideología. Con posterioridad, Tribe (2010, citado en Espeso y Pastor, 2015: 16) rectificó para postular la "indisciplina" en este campo de estudios, advirtiendo la existencia de dos formas irreconciliables de producir conocimiento conforme cosmovisiones, posicionamientos e intereses antagónicos: "The business of Tourism" vs. "Tourism Social Science". Ambas, según una u otra forma de representar el turismo y su espacialidad, se relacionan aquí con la idea de "plataforma científico-céntrica" y plataforma científico-crítica, respectivamente (figura 2).

Definitivamente, con independencia de la disciplina y del enfoque aplicado en la investigación del turismo actual, es responsabilidad del investigador decantarse por una u otra corriente: la primera, carente de profundización teórica, limitada al análisis de la actividad económica reproduciendo sin cuestionamiento la metodología comúnmente

6 Empíricamente se ha comprobado que el ritmo de crecimiento de la desigualdad aumenta progresivamente conforme se intensifica y expande la política económica neoliberal, en contradicción con lo que se pretende transmitir desde los centros de poder político-económico y mediático: "desde el inicio del presente siglo, la mitad más pobre de la población mundial solo ha recibido el 1\% del incremento total de la riqueza mundial, mientras que el 50\% de esa «nueva riqueza» ha ido a parar a los bolsillos del 1\% más rico" (Oxfam, 2016: 2). 
aplicada; la segunda, más reflexiva y crítica con los resultados, interesada en aportar su visión preocupada por la dimensión social del turismo (Osorio, 2005: 53). La pregunta que nos deberíamos formular para comprender qué tipo de conocimiento estaremos generando como geógrafos especializados en el campo de estudios del turismo es: ¿a qué percepción y racionalidad geográfica o social responde nuestra representación espacial del turismo? ¿Estamos facilitando la producción de un espacio social del turismo? O, por el contrario, ¿nuestras representaciones limitan la percepción del turismo a un espacio economíamundo al margen de la esencia de las relaciones sociales?

\section{Figura 2}

\section{CORRIENTES Y PLATAFORMAS EN LA REPRESENTACIÓN ESPACIAL DEL TURISMO}

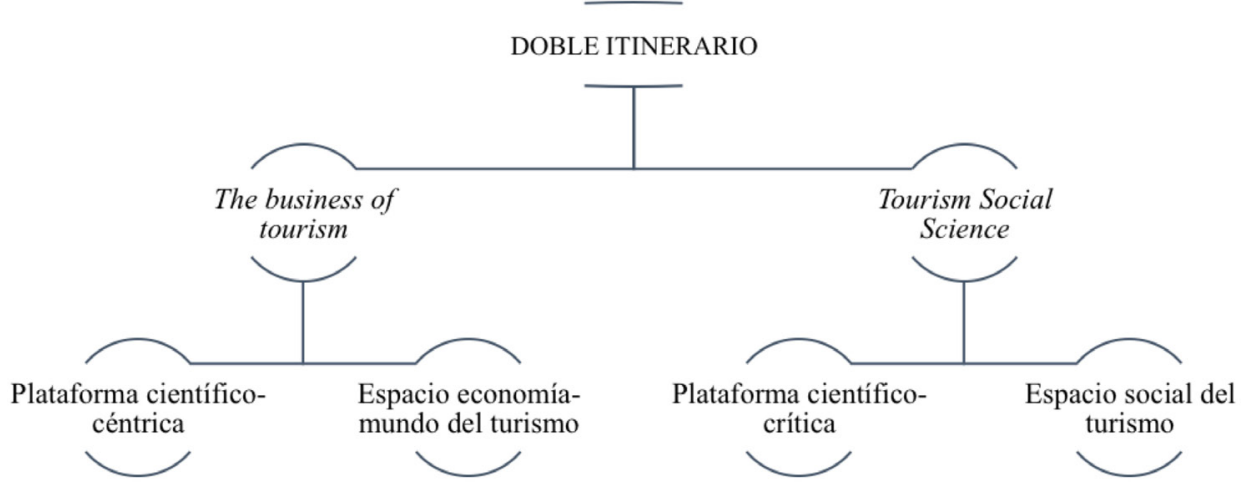

Fuente: Elaboración propia.

\subsection{La representación espacial del turismo según una racionalidad científico-cén- trica}

Tanto la "plataforma científico-céntrica" como la de "interés público" caracterizadas por Jafari (2005: 35) encuentran en la representación sistémica del turismo una forma de defender los intereses de aquellos que promueven la percepción de una "institución global" y negocio devenido en "mega-industria". Concretamente, desde la universidad se reafirma la utilidad de la teoría de sistemas para "reconocer procesos complejos donde las sociedades, los territorios o las economías articulan partes que sumadas configuran una totalidad funcional" (Vera et al. 1997: 38), algo no exento de sesgos condicionantes del tipo de decisiones y conductas promovidas al fijar la atención en unos aspectos imposibilitando el desarrollo de otros (Lazzarotti, 2007: 266).

A nivel académico se ha impuesto la parcialidad de fuerzas impersonales que deciden los temas a tratar limitando el espíritu crítico de los estudiantes, así como el pensamiento constructivo, complejo e intelectual, transformando la universidad en una “escuela profesional” (García, 2005: 145; Gómez, 2007: 170-172). En la etapa actual 
se ha generalizado la idea de que el principal reto de la investigación turística es el de "una mayor relación del mundo de la universidad con la empresa" o con "el mundo profesional" (Barrado, 2001: 21; Jafari, 2005: 49; Pulido, 2008: 109). Esta predilección por la investigación económica o de mercado es la que reduce nuestras aspiraciones a un "conocimiento-regulación", relacionado en todo caso con "el fuerte auge de los enfoques técnicos que ofrecen una salida profesional más o menos segura, proceso que es paralelo a una despreocupación creciente por la dimensión crítica y el compromiso con el cambio social" (García; 2005: 144).

De acuerdo con Segrelles, el problema no está en el carácter aplicado que adquiere el enfoque geográfico en sí mismo - pues teoría y praxis son conceptos interdependientes - , sino en "la exaltación sin fisuras que está viviendo este tipo de Geografía y su utilización como pantalla que esconde carencias mucho más graves y otras realidades" (2002: 163). Como comprende Rodríguez: "la pretensión de una escuela neutral y apolítica esconde en realidad una profunda ideologización al seleccionar y legitimar unos conocimientos entre varios posibles, al elegir una determinada forma de presentarlos" (2000: 96).

Concretamente, la representación geográfica del sistema turístico a cargo de la "plataforma científico-céntrica" se ha caracterizado por sobredimensionar la función del mercado en la intermediación de dos grandes subsistemas — sectorial y territorial- . El espacio geográfico representado aglutina simultáneamente la idea de "destino turístico o territorio", conjunto de subsistemas morfológicos donde lo territorial adquiere sentido de mercancía y la "sociedad local", incluso, la condición de "recurso" - mano de obra, artesanía, tradiciones, etc.- (Vera et al., 1997: 60; 2011: 319; Barrado, 2004: 66; Cooper et al., 2007: 726). Desde esta perspectiva los "turistas" se convierten en objetivo de estrategias de marketing y segmentación, valorados exclusivamente por su capacidad de consumo.

Con otras palabras: las interdependencias entre el "sistema territorio" y el "sistema destino" se representan mediadas por las leyes del consumo y del comercio sin cuestionar el hecho de que los beneficios derivados del turismo repercuten directamente en el sistema destino a costa del sistema territorio. Tampoco se discute que quien detenta la propiedad de los medios de producción obtenga el mayor beneficio a costa de la población, recompensada por su servilismo con la generación de empleo y el mantenimiento de actividades tradicionales, así como con la conservación del territorio y paisajes privilegiados por su valor de cambio turístico, condicionado en todo caso por un sentido netamente estético y banalizado de lo patrimonial (Valenzuela, 1984: 7; Callizo, 1991: 147).

A pesar de que este modelo analítico netamente geográfico y de elevada complejidad es el más reproducido en la investigación del turismo (Simancas, 2016: 53; FernándezArroyo, 2019: 206), cabe pensar que "las industrias de servicios, como el turismo, en las que se basa una buena parte de las metas económicas del marketing a escala local, se han conceptualizado de manera inadecuada" (Hall, 2009: 63), señalando como principal problema su definición sistémica: "un aspecto «auto-organizado», cerrado y autónomo de la vida social en general" (Korstanje, 2013: 13). A esta forma de representar y percibir el turismo se le puede asociar un propósito e intencionalidad: "seguir conservando el orden y el «progreso» actual de su desarrollo, inhibiendo la reflexión crítica que tiene por fin desvelar y descubrir un mundo donde la injusticia, la pobreza, la inequidad y los 
problemas, tanto humanos como del medio ambiente, son parte de un orden funcional y estructural que no se ha reconvertido y que incide directamente en el turismo pero, también, en su conocimiento producido" (Castillo, 2011: 517-518).

De acuerdo con nuestro marco de trabajo diremos que tanto desde la Geografía Turística como desde la Geografía del Turismo lo que se ha venido representando es un espacio de producción y consumo concebido sobre la percepción de una sociedad enajenada de valores alternativos a los privilegiados según la lógica del capitalismo. La mirada falsamente lúcida de esta representación, la de un espacio economía-mundo del turismo, ignora la ideología que contiene en sí misma, obviando que lo social no es solo una componente más del sistema turístico, sino la constante que lo envuelve y da sentido. Las relaciones sociales propiciadas por el turismo se reducen así a una permuta económica según el principio de oferta y demanda. Esto hace que las relaciones sociales articuladas en torno a la idea de turismo sean jerárquicas, no entre iguales.

En definitiva, con este tipo de representación participamos en la creciente distinción de lugares y clases sociales, siempre bajo la lógica del beneficio individual y de la competitividad, no de la cooperación y de la responsabilidad de a quien le correspondería tomar consciencia de que lo que se está consumiendo, al fin y al cabo, es el lugar del que "otro" depende para su desarrollo vital. Todo ello responde a un proceso de negociación política, económica y cultural desde la que, a diferentes escalas, se viene a imponer un sentido de lugar artificial conforme al imaginario de la demanda turística. Se podría expresar, al respecto, que las posibilidades semánticas de diferentes disciplinas, entre ellas la Geografía, se han venido adaptando para revalidar el relato de los "apologetas" del turismo, sirviéndose cada vez más de un reconocimiento científico institucionalizado frente al que apenas cabe discusión.

\subsection{Hacia un conocimiento-emancipación producto de la plataforma científico- crítica del turismo}

Desde una perspectiva contraria, la revelada con las representaciones concebidas desde la plataforma científico-crítica, la Geografía adquiere un papel tan importante como limitado en tanto que quienes han sustentado la idea de un contra-saber para con la producción del espacio inducida por esta industria pronto han sido desprestigiados y silenciados (Muñoz, 1992: 20; Bianchi, 2009: 496). El mayor problema para desarrollar la corriente científico-crítica en la investigación es la falta de referencias sobre las que apoyar el estudio del turismo con enfoque geográfico, especialmente en el caso español (Murray, 2015: 9-10). A ello se añade la compleja representación sistémica de un espacio social que implica dejar de concebir a la sociedad como parte de un encadenamiento productivo, lo que limita aún más su número de adeptos (Tribe, 2005: 7; Hall y Page, 2006: 280; Pearce, 2012: 136-137).

El enfoque sistémico con perspectiva sociológica tiene como núcleo de su representación la noción de "hecho social", planteando la posibilidad de aislarlo y comprenderlo objetivamente, no solo a través de sus formas y formalismos, coactivos en nuestras interpretaciones, sino accediendo a él a través de sus diversas "representaciones sociales", interpelándose o excluyéndose, fusionándose unas en otras o separándose (Durkheim, 
2001: 25 y 203) ${ }^{7}$. La teoría social del espacio sirve de base para cuestionar la representación de la sociedad como un análogo del sistema turístico dado y pasar a concebirse como creadora de sus propias estructuras y sentidos autorreferenciales o "de diferenciación" en un "entorno" igualmente delimitado por su alcance social (Osorio, 2007: 468).

El problema viene al intentar sistematizar el amplio abanico de relaciones sociales que a diferencia de las de tipo económico no están contenidas en marcos estables ni de cierta regularidad, pues se desenvuelven complejas e incluso imposibles de prever. Algunos intentos por adoptar esta perspectiva al enfoque sistémico del turismo tienen como referencia el sistema social de Niklas Luhmann (1984), teoría notablemente silenciada en España como afirma Urteaga (2010: 303). Dicho marco analítico nos permite definir los subsistemas funcionales - sistema político, sistema científico, sistema mediático, etc.del "hecho" turístico en relación al entorno social (Osorio, 2007).

Este tipo de representación de escaso recorrido en la investigación geográfica del turismo amplía el espacio de percepción de la "plataforma científico-céntrica" por la que se privilegia la faceta mercadológica y estadística del fenómeno para trabajar en la relación turismo-sociedad, más allá de los límites del mercado (Lazzarotti, 2007: 266 y ss.). Expresado de otro modo: si la percepción de esta práctica prescindiera de las funciones y actividades relacionadas con la economía del turismo, ¿qué nos quedaría? Los adscritos a la corriente de los negocios o "business of tourism" dirían: nada. Mientras que por el contrario los interesados en adoptar una mirada crítica de corte sociológico responderían: una parte del espacio social, los deseos, las aspiraciones y las posibilidades de cada comunidad para desarrollar nuevas formas de relacionarse social y espacialmente.

Esto no quiere decir que se deba obviar la importancia económica del turismo. Es ilógico o surrealista hablar en estos momentos de "des-mercantilizar" esta práctica. No obstante, aunque no se trata de eso, debemos explicar los motivos por los que surge un nuevo posicionamiento frente al convencionalismo con el que se percibe y concibe el turismo condicionando la producción de su espacio y la funcionalización del lugar. A nuestro parecer, y de acuerdo con Hiernaux (2006: 421-422), lo más significativo de este giro no es otra cosa que el rechazo a la representación del turismo "como un fenómeno que se puede aislar de la sociedad en la cual se inserta, y que el observador interroga desde un mirador distante y externo al fenómeno".

Por el momento, las investigaciones de corte social se han limitado primordialmente a aplicar un enfoque cualitativo desprestigiado durante mucho tiempo (Phillimore y Goodson, 2004: 4). De acuerdo con Woog (1989: 20, citado en Tribe, 2004: 47), el objeto de la corriente "Tourism Social Science" no debería ser tanto situar este campo de estudios al nivel de ciencia, tal y como pretende la "plataforma científico-céntrica" al aplicar el enfoque sistémico, sino el de reconocer que no puede ser así pero que se pueden generar explicaciones con rigor científico evidenciando lo inconveniente de priorizar ciertos aspectos y valores relacionados con la forma convencional de percibir y representar el turismo.

7 Durkheim (2001: 47-48) definió el "hecho social" como "resultante de la vida común, un producto de los actos y las reacciones que se efectúan entre las conciencias individuales; y si resuena en cada una de ellas, es en virtud de la energía especial que debe precisamente a su origen colectivo. Si todos los corazones vibran al unísono, no es debido a una concordancia espontánea y preestablecida; es que una misma fuerza las mueve en el mismo sentido. Cada uno es arrastrado por todos". 
En este sentido, la investigación adscrita a la plataforma científico-crítica se caracterizará por: 1) la emancipación de los marcos convencionales; 2) un uso consciente del lenguaje; 3) la identificación del origen e intencionalidad de la representación; 4) la deslegitimación del origen de la naturalización del turismo como inevitable; 5) el rechazo del determinismo económico; 6) y la representación de los procesos y estructuras por los que se generan desigualdades y relaciones de dominio y dependencia (Tribe, 2008; Espeso y Pastor, 2015: 18).

En el caso geográfico proponemos adoptar el marco analítico de la Geografía del Turismo en parte por su mayor recorrido y reconocimiento académico y social, sirviéndonos de los resultados obtenidos para invertir su relato con un análisis empírico-crítico capaz de descubrir los conflictos e intencionalidades de la ocultación y subversión de todo sentido de lugar, espacio y sociedad, para plantear alternativas a esa mercantilización de lugares que, a modo de collage, son transformados en escenarios aptos para su conversión deliberada en artículos de consumo (Hall, 2009: 124-125; Fernández-Arroyo, 2019: 261 y ss.).

Descubrir la estructura profunda que oculta el sistema de signos y símbolos del espacio economía mundo del turismo representado por la Geografía del Turismo como base para la concepción de un espacio social del turismo, en el mismo proceso constructivo de una Geografía Social del Turismo, debería servir para transformar la práctica social y espacial del turismo a la vez que nosotros mismos nos vamos transformando: un planteamiento utópico, no de imposible cumplimiento, tomando consciencia de que ni la representación de este espacio de esperanza ni de ningún otro podrá agotar la irreductibilidad ontológica del mismo (Pierce y Martin, 2015: 1289).

\section{CONCLUSIONES}

Como parece evidente, el turismo antes que una actividad económica es una práctica social cuya característica fundamental es la movilidad de un determinado grupo social. Es esta posibilidad de viajar la que se ha venido limitando con el tiempo a una idea de "turismo" alejada del concepto de "hospitalidad", fuertemente constreñido por la racionalidad de las relaciones entre viajeros y anfitriones que adquieren un sentido desigual, puramente mercantil en favor de los primeros $^{8}$. Con la práctica del turismo asumimos que la acogida o recibimiento de los visitantes se limita a un pago, a un intercambio comercial, siendo esto lo único que se puede obtener del turista. O, desde otra visión, en el papel de turistas: pensamos que la mejor si no la única aportación que podemos ofrecer al lugar visitado es nuestro dinero, inversión que en la mayoría de las ocasiones solo beneficia a agencias intermediarias y grandes empresas de capital des-territorializado.

La Geografía que ha adaptado sus marcos analíticos a las técnicas de los negocios y del marketing participa activa y voluntariamente en la profundización de dicha realidad, representando su objeto de estudio como un "producto" susceptible de comercialización. De esta forma, lo rural desde la perspectiva de lo urbano o lo periférico desde la lógica del

8 El Diccionario de la Real Academia Española define "hospitalidad", como: 1. f. Virtud que se ejercita con peregrinos, menesterosos y desvalidos, recogiéndolos y prestándoles la debida asistencia en sus necesidades; 2. f. Buena acogida y recibimiento que se hace a los extranjeros o visitantes; 3 . f. Estancia de los enfermos en el hospital. 
centro se pone de "moda" y se trata como "recurso", ocultando sus miserias para mostrar una cara amable conforme al canon occidental de lo estético y del buen gusto. Frente a ello, el actual "posicionamiento sociocultural" ha dejado de ignorar que la filosofía e ideología impulsora del reto del desarrollo en el medio rural, o en la periferia, "se ha fundamentado en un tejer y destejer para estar siempre en el principio" (García y Espejo, 2019: 2). De ahí que cada vez se considere más importante "desvelar las funciones que el turismo le proporciona al capitalismo al dar salida al capital excedente mediante la expansión hacia las nuevas periferias" (Blázquez, 2012: 8).

Las representaciones que asociamos a la idea de "plataforma científico-céntrica", propias de la Geografía Turística y de la Geografía del Turismo, reproducen un "conocimiento-regulación" que profundiza en la propia racionalidad de la práctica del turismo limitando la imaginación sobre otras aspiraciones vinculadas al hecho de viajar. El sentido del viaje transmitido con la difusión de imágenes, imaginarios y valores a cargo de autorizados especialistas o "commentators" se disfraza de neutralidad: grandilocuentes relatos ocultan el acusado impacto ecológico y social al imponer una interesada y excluyente preocupación por el buen funcionamiento del orden social y económico para el que la actividad turística actúa como fiable indicador (Phillimore y Goodson, 2004: 14; Hall y Page, 2006: 6; Prats, Herrero y Torrego, 2017: 134).

De este modo, la Geografía en general y, muy especialmente, su rama especializada en el campo de estudios del turismo denota una clara preferencia por los "contactos e intercambios con las empresas y la administración, pero no con otras organizaciones sociales en cuya proximidad se percibe mejor los problemas que preocupan a los ciudadanos" (Segrelles, 1998). Esto reduce la discusión y el debate epistemológico, así como las aspiraciones de los geógrafos para ser "socialmente útiles" (Troitiño, 1992: 71). Plantear esta idea o reflexión en un contex to académico donde predominan los estudios con perspectiva mercadológica no deja de ser tan subversivo como problemático, pues cuestiona el relato institucional, empresarial y universitario que se fomenta. No obstante, sin la crítica y la autocrítica sobre la base de lo investigado difícilmente se puede avanzar en la generación de conocimiento, al menos de un "conocimiento-emancipación".

Tal conclusión no pretende ser finalista, sino que aspira a servir de soporte dialógico para el debate sobre la existencia o necesaria construcción de una Geografía Social del Turismo cuyo objeto sea la representación de un espacio de esperanza o espacio social del turismo abierto a prácticas radicalmente alternativas, desde la raíz de su racionalidad. La plataforma científico-crítica encargada de este proyecto ha tomado plena consciencia y asume la responsabilidad de que sus representaciones incidan de un modo u otro, en mayor o menor medida, en el sentido de la práctica social y espacial del turismo, así como, por ende, en la racionalidad que hay en la producción del espacio comprometido. No quepa duda de que, con nuestra acción consciente, la de una investigación emancipada, estaremos instrumentalizando la noción de turismo para que actúe como intercambiador de ideas y vector de cambio social. 


\section{BIBLIOGRAFÍA}

ALBET, A. (1988): «Valoració dels lligaments entre geografia radical i geografia humanística», Documents d'Anàlisi Geográfica, nº 13, pp. 5-18.

ALMIRÓN, A. V. (2004): «Turismo y espacio. Aportes para otra Geografía del Turismo», Espaço e Tempo, $\mathrm{n}^{\circ} 16$, pp. 166-180.

ANTON, S. y GONZÁLEZ, F. (2008): A propósito del turismo: la construcción social del espacio turístico. Barcelona, Universitat Ouberta de Catalunya.

ARNADIS, R. (2017): La adaptación al uso turístico de los recursos culturales. Una propuesta de evaluación para una comprensión más equilibrada de la actividad turística. Valencia, Universidad de Valencia. Tesis Doctoral.

BAILEY, G. (2014): «La racionalidad espacial y su persistencia en la era global», Revista de Estudios Urbanos y Ciencias Sociales (URBS), vol. VII (1), pp. 89-108.

BARRADO, D. A. (2001): «El papel de la geografía en la formación de técnicos en turismo», Cuadernos de Turismo, $\mathrm{n}^{\circ}$ 7, pp. 7-22.

BARRADO, D. A. (2004): «El concepto de destino turístico. Una aproximación geográfico-territorial», Estudios Geográficos, n 160 , pp. 45-68.

BARRADO, D. y ÁVILA, R. (2010): «El tratamiento del espacio y de la actividad turística», en Galiana Martín, L. y Vinuesa Angulo, J. (Ed.): Teoría y práctica para una ordenación racional del territorio. Madrid, Síntesis, pp. 153-180.

BAUMAN, Z. (1998): Globalization: The Human Consequences. New York, Columbia University Press.

BENACH, N. y ALBET, A. (2010): La perspectiva postmoderna de un geógrafo radical. Barcelona, Icaria Editorial.

BENKO, G. (2000): «La recomposición de los espacios», Geographicalia, n 38, pp. 3-10.

BIANCHI, R. V. (2009): «The «Critical Turn» in Tourism Studies: A Radical Critique», Tourism Geographies, vol. XI (4), pp. 484-504.

BLÁZQUEZ, M. (2012): «Prólogo», en BUADES, E.; CAÑADA, E. y GASCÓN, J.: El turismo en el inicio del milenio: una lectura crítica a tres voces. Madrid, Foro de Turismo Responsable, Red de Consumo Solidario, PicuRabicu y Espacio por un Comercio Justo, pp. 7-9.

BLÁZQUEZ, M. y CAÑADA, E. (Eds.) (2011): Turismo placebo. Nueva colonización turística del Mediterráneo a Mesoamérica y El Caribe. Lógicas espaciales del capital turístico. Managua, Editorial Enlace.

CALABUIG, J. y MINISTRAL, M. (2003): Manual de Geografía turística de España. Madrid, Síntesis.

CALLIZO, J. (1991): Aproximación a la Geografía del turismo. Madrid, Síntesis.

CAÑIZARES, M. C. (2013): «Sostenibilidad y turismo: de la documentación internacional a la planificación en España “Horizonte 2020”», Boletín de la Asociación de Geógrafos Españoles, nº 61, pp. 67-92.

CASEY, E. (1996): «How to Get from space to place in a fairly short stretch of time. Phenomenological prolegomena», en FELD, S. y BASSO, K. H. (Coords.): Sense of place. Santa Fe, School of American Research Press, pp. 13-52. 
CASTILLO, M. (2007): «La investigación y epistemología del turismo: aportes y retos», Revista Hospitalidade, vol. IV (2), pp. 79-95.

CASTILlO, M. (2011): «Epistemología Crítica do Turismo: ¿Que é isso?», Turismo em Análise, vol. 22 (3) pp. 516-538.

CASTILLO, M. y PANOSSO, A. (2011): «Implicaciones epistemológicas en la investigación turística», Estudios y Perspectivas en Turismo, n ${ }^{\circ}$ 20, pp. 384-403.

COHEN, E. (2005): «Major trends in contemporary tourism», Política y Sociedad, vol. XLII (1), pp. 11-24.

COOPER, Ch. et al. (2007): El Turismo. Teoría y práctica. Madrid, Síntesis.

CORREYERO, B. (2003): «La propaganda turística española en los años del aislamiento Internacional», Historia y Comunicación Social, $n^{\circ}$ 8, pp. 47-61.

DE SOUSA, B. (1993): «O social e o político na transição pós-moderna», Lua Nova: Revista de Cultura e Política, no 31, 20 de abril de 2019. Centro de Estudos de Cultura Contemporânean CEDEC). Disponible en http://www.scielo.br/scielo.php?pid=S0102$-64451993000300010 \&$ script=sci_arttext\&tlng=pt

DE SOUSA, B. (1998): De la mano de Alicia. Lo social y lo político en la postmodernidad. Santa Fe de Bogotá, Siglo del Hombre Editores.

DE SOUSA, B. (2003): Crítica de la razón indolente. Contra el desperdicio de la experiencia. Para un nuevo sentido común: la ciencia, el derecho y la política en la transición paradigmática, vol. I. Bilbao, Desclée de Brouwer. Traducción coordinada por J. Herrera.

DE SOUSA, B. (2006): Renovar la teoría crítica y reinventar la emancipación social. Buenos Aires, CLACSO.

DURKHEIM, E. (2001): Las reglas del método sociológico. México, Fondo de Cultura Económica.

ESPESO, P. y PASTOR, M. J. (2015): «El giro crítico en los estudios turísticos: revisión del concepto del «turismo de la esperanza»», en NEL-LO, M.; CAMPOS, B. L.; y SOSA, A. P. (Eds.); PÉREZ, D.; y BERTRAN, J. A. (Coords.): Temas pendientes y nuevas oportunidades en turismo y cooperación al desarrollo. California, Universidades de Quintana Roo, Rovira i Virgili y del Caribe, pp. 14-22.

FERNÁNDEZ-ARROYO, A. (2019): El espacio social del turismo y su producción como territorio patrimonial. Aplicación a Castilla-La Mancha. Ciudad Real, Universidad de Castilla-La Mancha, Tesis Doctoral (Inédita).

GARCÍA, M. D. (2005): «Enfoques críticos y práctica de la geografía en España. Balance de tres décadas (1974-2004)», Documents d'Analisis Geográphica, n 45, pp. 139-148.

GARCÍA, R. y ESPEJO, C. (2019): «El círculo vicioso de la despoblación en el medio rural español: Teruel como caso de estudio». Estudios Geográficos, vol. LXXX, n ${ }^{\circ}$ 286 , pp. 1-5.

GÓMEZ, S. (2007): «Retos y desafíos de la educación superior y la investigación turística en México», en ESPINOSA, M. (Coord.): Tendencias de investigación turística a principios del siglo XXI. México, Instituto Politécnico Nacional, pp. 159-180.

HALL, C. M. (2009): El turismo como ciencia social de la movilidad. Madrid, Síntesis.

HALL, C. M. y PAGE, S. J. (2006): The Geography of Tourism and Recreation. Environment, Place and Space. Londres y Nueva York, Routledge. 
HIERNAUX, D. (2006): «Geografía del turismo», en LINDÓN, A. y HIERNAUX, D. (Dir.): Tratado de Geografía Humana. Barcelona, Anthropos, pp. 401-432.

HIERNAUX, D. (2008a): «El giro cultural y las nuevas interpretaciones geográficas del turismo», Espaço e Tempo, no 23, pp. 177-187.

HIERNAUX, D. (2008b): «Una década de cambios: La Geografía humana y el estudio del turismo», Scripta Nova: Revista electrónica de Geografía y Ciencias Sociales, vol. XII, no 270 (87), 20 de abril de 2017. Disponible en http://www.ub.edu/geocrit/ sn/sn-270/sn-270-87.htm

HIERNAUX, D. (2014): «Territorio y turismo en los países emergentes en un contexto de globalización: imaginario y realidad», en FORONDA, C. et al. (Coords.): Espacios turísticos e inteligencia territorial. Respuestas ante la crisis. Actas del XIV Coloquio de Geografía del turismo, ocio y recreación. Sevilla, Red de Impresión, pp. 143-156.

IBAÑEZ, J. (2017): «Introducción», en IBAÑEZ, J. (Ed.): En la Era de la Posverdad. 14 ensayos. Barcelona, Calambur, pp. 11-36.

JAFARI, J. (2005): «El turismo como disciplina científica». Política y Sociedad, vol. XLII (1), pp. 39-56.

KORSTANJE, M. E. (2013): «Epistemología del turismo: teoría del sistema onírico», Palermo Business Review, $\mathrm{n}^{\circ}$ 10, pp. 7-20.

LACOSTE, Y. (1978): Geografía del subdesarrollo. Barcelona, Ariel.

LAZZAROTTI, O. (2007): «Tourisme et Géographie: le grand derangement», en STOCK, M. (Coord.): Le tourisme. Acteurs, lieux et enjeux. París, Belin, pp. 259-281.

LEFEBVRE, H. (2013): La producción del espacio. Traducción, prólogo y notas de Emilio Martínez. Madrid, Capitán Swin [primera edición de 1974].

LINDÓN, A. (2004): «Las huellas de Lefebvre sobre la vida cotidiana», Revista Veredas, vol. V, n ${ }^{\circ} 8$, pp. 39-60.

LINDÓN, A. y HIERNAUX, D. N. (Dirs.) (2006): Tratado de Geografía Humana. Barcelona, Anthropos.

LÓPEZ (2018): «Contra el neoliberalismo académico. A propósito de la tesis doctoral de M. E. Valdunciel», Con-Ciencia Social (segunda época), nº 1, pp. 153-159.

LUIS GÓMEZ, A. (1983): «La Geografía Humana: ¿de ciencias de los lugares a ciencia social?», Geo Crítica: Cuadernos críticos de Geografía Humana, n 48, 22 de junio de 2019. Disponible en http://www.ub.edu/geocrit/geo48.htm

LUIS GÓMEZ, A. (1987): «La evolución internacional de la geografía del ocio», Geo Crítica: Cuadernos críticos de Geografía Humana, nº 69, pp. 3-54.

MALPAS, J. (2015): «Thinking topographically: Place, Space, and Geography», Documents d'Anàlisi Geogràfica, no 61/2, pp. 199-229, 22 de octubre de 2019. Universitat Autònoma de Barcelona. Disponible en http://jeffmalpas.com/downloadable-essays/

MASSEY, D. (1984): «Introduction: Geography matters!», en MASSEY, D. y ALLEN, J. (Eds.): Geography matters! Cambridge, Cambridge UniversityPress, pp. 1-11. Traducción al español del original, en ALBET, A. y BENACH, N. (2012): Doreen Massey. Un sentido global del lugar. Icaria, Barcelona, pp. 95-111.

MASSEY, D. (1991): «A Global Senseof Place», MarxismToday, n 38, pp. 24-29. Traducción al español del original, en ALBET, A. y BENACH, N. (2012): Doreen Massey. Un sentido global del lugar. Icaria, Barcelona, pp. 112-128. 
MASSEY, D. (2004): «Lugar, identidad y geografías de la responsabilidad en un mundo en proceso de globalización», Treballs de la Societat Catalana de Geografía, n 57 , pp. 77-84.

MORALES, M. (2007): «Hacia una comprensión del turismo moderno y posmodernos», en ESPINOSA, M. (Coord.): Tendencias de investigación turística a principios del siglo XXI. México, Instituto Politécnico Nacional, pp. 121-156.

MUÑOZ, F. (1992): Crítica de la economía turística. Enfoque de oferta versus enfoque de demanda. Madrid, Universidad Complutense, Tesis Doctoral.

MURRAY, I. (2015): Capitalismo y turismo en España. Del "milagro económico" a la "gran crisis". Barcelona, AlbaSud.

ORTEGA VALCÁRCEL, J. (2000): Los horizontes de la geografía: teoría de la geografía. Barcelona, Ariel.

ORTEGA VALCÁRCEL, J. (2004): «La geografía para el siglo XXI», en ROMERO, J. (Coord.): Geografía Humana. Procesos, riesgos e incertidumbres en un mundo globalizado. Barcelona, Ariel, pp. 24-54.

OSORIO, M. (2005): «Hacia la construcción del objeto de estudio del turismo desde una perspectiva materialista crítica», Pasos: Revista de Turismo y Patrimonio Cultural, vol. III (1), pp. 41-61.

OSORIO, M. (2007): «El carácter social del turismo. Un análisis sistémico sobre su complejidad», Estudios y Perspectivas en Turismo, nº 16, pp. 464-492.

OXFAM (2016): Una economía al servicio del 1\%. Acabar con los privilegios y la concentración de poder para frenar la desigualdad extrema, 28 de julio de 2019, Oxford Committee for Famine Relief. Disponible enhttps://www-cdn.oxfam.org/s3fs-public/ file_attachments/bp210-economy-one-percent-tax-havens-180116-es_0.pdf

PEARCE, D. G. (2012): Frameworks for Tourism Research. New Zealand, Victoria University of Wellington.

PEARCE, D. G. (2013): «Comprometiéndose con el mundo. América Latina y la internacionalización de la investigación en turismo», Estudios y Perspectivas en Turismo, vol. XXII, pp. 908-925.

PHILLIMORE, J. y GOODSON, L. (2004): «Progress in qualitative research in tourism. Epistemology, ontology and methodology», en PHILLIMORE, J. y GOODSON, L. (Eds.): Qualitative research in tourism. Ontologies, epistemologies and methodologies. London y New York, Routledge, pp. 3-29.

PIERCE, J. y MARTIN, D. G. (2015): «Placing Lefebvre», Antipode, vol. XLVII (5), pp. $1.279-1.299$.

PILLET, F. (2008): Espacio y ciencia del territorio: proceso y relación global-local. Madrid, Biblioteca Nueva.

PILLET, F. (2012): «El turismo de interior en la España peninsular: el patrimonio territorial como destino turístico», Boletín de la Asociación de Geógrafos Españoles, $\mathrm{n}^{\circ}$ 59, pp. 345-366.

PILLET, F. (2016): «¿A qué llamamos Patrimonio Territorial como destino turístico?», Plataforma digital ibero-americana para la difusión del trabajo científico (GeocrítiQ), 28 de julio de 2019. Disponible en http://www.geocritiq.com/2016/06/a-que-llamamospatrimonio-territorial-como-destino-turistico/ 
PRATS, F.; HERRERO, Y.; y TORREGO, A. (2016): La Gran Encrucijada. Sobre la crisis ecosocial y el cambio de ciclo histórico. Madrid, Libros en Acción.

PRIESTLEY, G. K. (1997): «El turismo de interior en el conjunto del turismo español», en VALENZUELA, M. (Coord.): Los turismos de interior. El retorno a la tradición viajera. Madrid, Universidad Autónoma de Madrid y Asociación de Geógrafos Españoles, pp. 261-270.

PULIDO, J. I. (2008): «La estructura de los mercados turísticos. Especial referencia al turismo rural», en CEBRIÁN, F. (Coord.): Turismo rural y desarrollo local. Cuenca, Universidad de Castilla-La Mancha, pp. 109-121.

RODRÍGUEZ, F. (2000): La actividad humana y espacio geográfico. Madrid, Síntesis.

ROSALES, R. (2006): «Geografía económica», en LINDÓN, A. y HIERNAUX, D. (Dir.): Tratado de Geografía Humana. Barcelona, Anthropos, pp. 129-146.

SÁNCHEZ VÁZQUEZ, A. (2006): «Ética y marxismo», en BORON, A. A.; AMADEO, J.; GONZÁLEZ, S. (Comps.): La teoría marxista hoy. Problemas y perspectivas. Buenos Aires, Consejo Latinoamericano de Ciencias Sociales -CLACSO_ pp. 297-307.

SANCHO A. (Dir.) (1998): Introducción al Turismo. UNWTO e-library, 14 de abril de 2019. Disponible en http://www.e-unwto.org/doi/abs/10.18111/9789284402694

SANTOS, M. A. (1990): Por una Geografía Nueva. Madrid, Espasa-Calpe.

SANTOS, M. A. (1996): De la totalidad al lugar. Barcelona, Oikos-Tau.

SANTOS, M. A. (2000): La naturaleza del espacio. Técnica y tiempo. Razón y emoción. Barcelona, Ariel.

SEGRELLES, J.A. (1998): «La Geografía y los usuarios de la investigación geográfica en España», Scripta Nova: Revista electrónica de Geografía y Ciencias Sociales, $\mathrm{n}^{\circ} 30$, 25 de abril de 2019. Disponibe en http://rua.ua.es/dspace/handle/10045/2207

SEGRELLES, J. A. (2002): «Luces y sombras de la geografía aplicada», Documents d'Anàlisi Geogràfica, $\mathrm{n}^{\circ}$ 40, pp. 153-172.

SHAW, G. y WILLIAMS A. M. (1998): Critical Issues In Tourism. A Geographical Perspective. Oxford, Blackwell.

SIMANCAS, M. R. (Coord.) (2016): La planificación y gestión territorial del turismo. Madrid, Síntesis.

SMITH, D. M. (1980): Geografía Humana. Barcelona, Oikos Tau.

SOJA, E. W. (1997): «El tercer espacio. Ampliando el horizonte de la imaginación geográfica», Geographikós, vol. VIII (2), pp. 71-76.

SOJA, E. W. (2003): Thirdspace: journeys to Los Angeles and other real-and-imagined places. Cambridge, Blackwell.

TRIBE, J (2004): «Knowing about tourism. Epistemological issues», en PHILIMOR, J. y GOODSON, L. (Eds.): Qualitative Research in Tourism. Ontologies, epistemologies and methodologies. London, Routledge, pp. 46-62.

TRIBE, J (2005): «New Tourism Research», Tourism Recreation Research, vol. XXX (2), pp. 5-8.

TROITIÑO, M. Á. (1992): «Dimensión aplicada y utilidad social de la geografía humana», Ería, $\mathrm{n}^{\mathrm{o}} 27$, pp. 57-73. 
TROITIÑO, M.A. y TROITIÑO, L. (2018): «Visión territorial del patrimonio y sostenibilidad del turismo», Boletín de la Asociación de Geógrafos Españoles, n ${ }^{\circ}$ 78, pp. 212-244.

URRY, J. (2011): «¿Complejidades y futuros?», CIDOB d'afersinternacionals, $\mathrm{n}^{\circ}$ 95, pp. 11-20.

URTEAGA, E. (2010): «La teoría de sistemas de Niklas Luhman», Contrastes, ${ }^{\circ}$ 15, pp. 301-317.

VALENZUELA, M. (1984): «El uso recreativo de los espacios naturales de calidad. (Una reflexión sobre el caso español)», Estudios Turísticos, n 82, pp. 3-14.

VALENZUELA, M. (1986): «Turismo y territorio», Estudios Turísticos, nº 90, pp. 47-56.

VERA, J. F. et al. (Coord.) (1997): Análisis territorial del turismo. Una nueva geografía del turismo. Barcelona, Ariel.

VERA, J. F. et al. (Coord.) (2011): Análisis territorial del turismo y planificación de destinos turísticos. Valencia, Tirant lo Blanch.

WILLIAMS, S. (1994): Tourism Geography. London \& New York, Routledge. 
